Research Article

\title{
High Performance Work Systems Reality in Multinational Subsidiaries: Lessons from South Eastern European Periphery
}

\author{
Loukas K. Tsironis \\ Department of Business Administration, University of Macedonia, Greece \\ loukas@uom.edu.gr \\ *Correspondence: loukas@uom.edu.gr
}

Received: $14^{\text {th }}$ November 2020; Accepted: $18^{\text {th }}$ January 2021; Published: $1^{\text {st }}$ February 2021

Abstract: Recently, a number of studies have focused on the positive relationship between high-performance work systems (HPWS) and organizational performance and its underlying mechanisms. European countries in general and former communist countries is particular have been largely overlooked. It seems crucial to assess the importance of HPWS and its impact on organizational performance in MNC subsidiaries operating in the region. The study examines the sequential mediation of job satisfaction and organizational citizenship behavior (OCB) in the HPWS-organizational performance link. Quantitative data was collected from 181 participants working in MNC subsidiaries operating in the Balkan region (Romania, Serbia, Bulgaria, Albania, FYROM, and Kosovo). The study employed Baron and Kenny (1986) approach to mediation analysis. Findings showed a positive relationship between HPWS and organizational performance. OCB had a partial mediating value in the HPWS performance link. Similarly, job satisfaction partially mediates the relationship between HPWS and organizational performance.

Keywords: High-Performance Work Systems; Multi-National Companies; subsidiary; Organizational Performance; job satisfaction; Organizational Citizenship Behavior; South Eastern Europe

\section{Introduction}

Since its introduction in literature, the notion of high-performance work systems (HPWS) has attracted attention both from HR research as well as practitioners due to its impact on employee and organizational performance (e.g. Camps \& Luna-Arocas, 2010; Fey et al., 2009; Delaney \& Huselid, 1996; Huselid, 1995; Ngo \& Foley, 2011; Takeuchi, Lepak and Chen, 2009; Takeuchi et al., 2007). In particular, HPWS (also known as high -involvement or commitment work systems) refers to a set of human resource (HR) practices that can contribute to increased organizational performance (Becker and Huselid, 1998; Delaney \& Huselid, 1996; Fey et al., 2009; Huselid, 1995). However, HPWS implementation and its relation with performance did not come without criticism. Even though the link between HPWS and organizational performance is widely reported across different national and organizational settings independent of size and age of the organization (Appelbaum et al., 2000; Bashir et al., 2011; Becker \& Huselin, 2008; Paauwe, 2009; Pfeffer, 1998), the relationship at the employee level is controversial, and the mechanisms affecting this link are still unknown. Critics of HPWS argue that the practices are a way to oppress even further the employee by increasing workload, work stress, and managerial control (Godarg, 2004; Guest, 2002) while HPWS advocate maintain that HPWS is associated with increased employee motivation (e.g. Fey, 2005), job satisfaction (Bashir et al., 2011), or organizational learning capability (Camps and Luna-Arocas, 2010).

Loukas K. Tsironis, “High Performance Work Systems Reality in Multinational Subsidiaries: Lessons from South Eastern European Periphery", Annals of Contemporary Developments in Management \& HR (ACDMHR), Print ISSN: 2632-7686, Online ISSN: 2632-7694, pp. 43-52, Vol. 3, No. 1, $1^{\text {st }}$ February 2020, Published by International Association of Educators and Researchers (IAER), DOI: 10.33166/ACDMHR.2021.01.005, Available: http://acdmhr.theiaer.org/archive/v3/v3n1/p5.html. 
Furthermore, the high majority of studies has been conducted in Western countries (e.g. Gittel et al., 2010) or rapidly emerging Asian markets (e.g. Liao et al., 2009; Takeuchi et al., 2007). Over the last few years, studies exploring the link between HR practices and performance have been conducted in European environments (e.g. Gooderham et al., 2008; Fey et al., 2009; Lertxundi \& Landeta, 2011; Savrou et al., 2007). However, the effect of host culture on the success of HR practices introduced has been largely neglected in a host of countries. Moreover, there is a gap in literature studies assessing the role of HPWS in organizations operating in the former communist bloc, with only a small number of studies incorporating Russian organizations (e.g. Fey et al., 2009). To date, the Balkan region has received very little interest in the organizational research in general and in the HR practices performance link in particular (Brewster \& Bennett, 2010; Kerekes et al., 2011; Savrou et al., 2007). Mittal (2010) argues that national culture will have an impact not only on the implementation of the HR practices but also on the success of certain practices at the organizational level. He rejects the notion of universal HR practices and argues that the replication of results from wested Anglo-Saxon or Asian cultures might prove difficult. Thus, it can be argued that the national and regional culture will impact the success and selection of HR practices used.

The current paper aims to unravel the link between HPWS and organizational performance by identifying gaps in the literature and proposing new routes of research. The present model suggests that the link between HPWS and organizational performance is mediated by both employee attitudes and behaviors, including job satisfaction and, in turn, organizational citizenship behavior (OCB). In doing so, this study focuses on MNC subsidiaries operating in 6 post-communist cultures in the Balkan region (Romania, Bulgaria, Serbia, Kosovo, Albania, and FYROM).

\section{Theoretical Background}

\subsection{HPWS and Organizational Performance}

HPWS is a set of non-financial performance tools and practices aiming at increasing individual and organizational performance by motivating the individual to internalize the organizational goals (BeltranMartin et al., 2008). HPWS aims at achieving competitive advantage rather than simply cost-cutting by investing in the individual. HWPS refers to the interaction between a set of different HR practices rather than focusing on isolated HR practices. Pfeffer (1998) introduced a list of seven HR practices under the name HPWS. There seems to be a lack of understanding on how to define and name the concept. For example, many studies use the notion of high involvement working systems to focus on the individual and his/her role in the organization. High involvement theory advocates argue that employees should be assigned a high level of organizational responsibility and be actively involved in the organizational decision-making process (Liao et al., 2009). A different school of thought uses the term HPWS emphasizing organizational performance (AlZgool et al., 2021) as the final goal in HR practices adoption (Gitell et al., 2009; Beltran-Marti et al., 2008). For this paper, HR practices are taken in a bundle and assessed accordingly will be defined as high-performance work systems (HPWS). Though theoretically, the different names come from different schools of thought, they all use similar HR practices. This is aimed to minimize possible confusion that might arise with the use of different HR bundle practices.

Research supporting the idea of a simple causal link between HPWS and organizational performance has recently come under scrutiny (Lau \& Ngo, 2004; Fey et al., 2009). Critics (Chi and Lin, 2011; Lau and Ngo, 2004; Ngo and Foley, 2011) argue that such a link is too simplistic and fails to account for moderating and mediating factors. Chi and Lin (2011) found that the relationship between HPWS and organizational performance is curvilinear rather than direct. In the high technology sector, the relationship increases as an organization matures. However, the study failed to find similar results in the manufacturing sector. The authors state that it is more common for the high technology sector to employ HPWS to achieve competitive advantage due to the fast-developing nature of the sector. Similarly, Lertxundi and Landeta (2011) found the national culture to be a partial mediating variable in the link between HPWS and organizational 
performance in Spanish MNCs. Other partial mediating variables in the HPWS organizational performance link were employee motivation (e.g. Fey, 2005), OCB (Wei et al., 2010), human resource flexibility (BeltranMartin et al., 2008), or organizational culture (Chow 2012).

H1: HPWS is positively related to organizational performance.

\subsection{Mediation of Job Satisfaction}

Employee job satisfaction has been positively linked to HPWS (Guest, 1997; Mackey and Boxall, 2007) and organizational performance (Jiang et al., 2011). In his study, Guest (1997) found HPWS implementation was related to job satisfaction. Employees working in departments with high levels of HPWS reported higher levels of job satisfaction. One possible explanation for this finding is that HPWS influences the employee levels of organizational commitment (Silverthome, 2004). Job satisfaction can be defined as a cluster of employee variables such as job security, compensation, non-monetary benefits, growth opportunity, and trust in management and the organizational context (Guest, 2004). Job satisfaction can be affected by both intrinsic and extrinsic variables. Intrinsic variables of job satisfaction can be job promotion and professional growth opportunity, whereas monetary compensation and benefits are extrinsic job satisfaction factors (Porter \& Lawler, 1968). It is argued that job satisfaction should involve both intrinsic and extrinsic factors (Alzyoud et al., 2019; Porter \& Lawler, 1968). However, job satisfaction scales focus extensively on extrinsic factors due to the ambiguity inherited by measuring intrinsic factors (Bashir et al., 2011). Huang and van de Vliert (2003) found that national culture plays a role in job satisfaction. The study conducted in organizations operating in 41 countries found that intrinsic job characteristics are positively related to levels of job satisfaction in high socio-economical cultures.

In contrast, extrinsic job characteristics are positively related to levels of job satisfaction in lower socioeconomical cultures. Similar results have been reported by Fey (2005), who found that high socio-economic cultures react positively towards intrinsic job characteristics and negatively to low job characteristics. In their study, Russian employees from a culture or high-power distance showed a positive relationship between extrinsic job characteristics and job satisfaction, whereas intrinsic job characteristics did not relate to job satisfaction. The authors argue that national culture plays an important role in the link between job characteristics and job satisfaction. Job satisfaction was positively linked to HR practices and general and HPWS in particular (Fey, 2005; Guest, 2004; Wu \& Chaturvedi, 2009). In organizations where HPWS is employed, workers exhibit a higher level of job commitment and job satisfaction due to their involvement in organizational decision making, increasing responsibilities, and job autonomy (Guest, 2004).

H2: Job satisfaction mediates the relationship between HPWS and organizational performance.

\subsection{OCB as a Mediator}

Organizational citizenship behavior (OCB) (Organ, 1997) refers to the employee collective work behavior at the organizational level. The concept refers to the extra work behavior that goes beyond the employee job description and attributions (Bateman and Organ, 1983; Umrani et al., 2019). By nature, OCB is not formally enforced or penalized (Organ, 1997). A study conducted on a sample of 239 executive of organizations operating in China found a strong positive relationship between HPWS and OCB (Cong,Chang and Cheung, 2010). Research (Pare et al., 2007) suggests that the implementation of HPWS at different sectors of the organization leads to an increase in the level of collective OCB.

However, OCB has previously been linked to improvements in individual and organizational performance (Podsakoff et al., 1997; Podsakoff et al., 2000). Furthermore, a number of studies found a link between OCB, job satisfaction, and employee performance (Murphy et al., 2002; Ishfaq et al., 2011; Kim, 2006). A strong positive relationship between OCB and job satisfaction has been reported by Murphy and colleagues (Murphy et al., 2002), with job satisfaction predicting the collective level of OCB. Furthermore, 
in his study, Buentello et al. (2008) also reported a positive link between OCB and organizational performance, with OCB mediating the relationship between TQM and organizational performance.

H3: OCB mediates the relationship between HPWS and organizational performance.

\subsection{Sequential Mediation}

Thus far, we have suggested the positive relationship between HPWS and organizational performance $(\mathrm{H} 1)$ as well as the mediating role of job satisfaction $(\mathrm{H} 2)$ and $\mathrm{OCB}(\mathrm{H} 3)$ in this relationship. Taken together, we posit the sequential mediation of job satisfaction and, in turn, OCB in the association between HPWS and organizational performance.

H4: HPWS is indirectly related to organizational performance through the mediating role of job satisfaction and in turn predicts OCB.

\subsection{Conceptual Framework}

Based on the critical appraisal of the literature, the current study proposes the following framework for study:

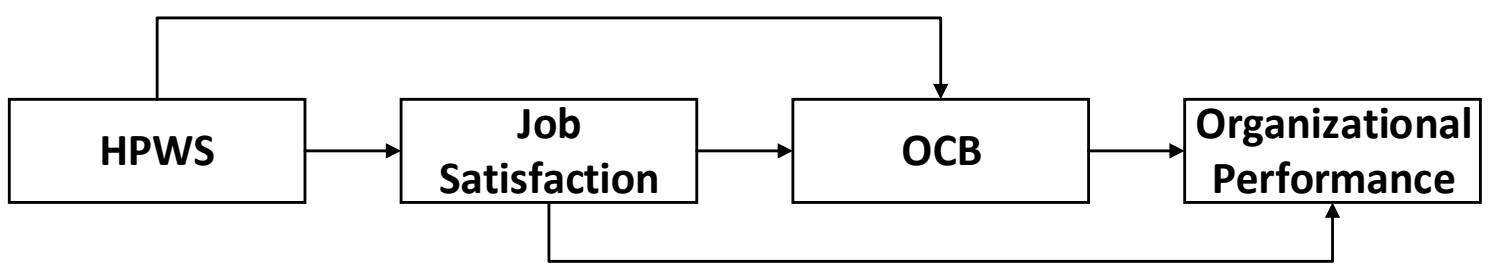

Figure 1. The hypothesized Model

\section{Current Study}

The purpose of the current study is to explore and analyze the interaction of high-performance measurements in a sample of MNC subsidiaries operating in post-communist Balkan states. The study looks at the relationship between HPWS and organizational performance and the mediating variables that might impact it. We hypothesis that job satisfaction will play a mediating role in the link between HPWS and organizational performance. HPWS will increase the levels of employee job satisfaction that in turn will lead to higher organizational performance. Furthermore, we assume that OCB will mediate the relationship between HPWS and organizational performance. HPWS will positively impact the collective levels of OCB that in turn will positively impact the financial, organizational performance.

A large number of studies come with a series of limitations in terms of adopted statistical methodology (lack of cause-and-effect) and limited study sample. Due to the focus on single countries, result generalization can prove difficult. A limited number of studies (e.g. Galag, 2004; Sahader and Demirbag, 2011; Svetlik et al., 2010) used multi-country analysis in the HRM context in general. Furthermore, there is a virtual gap in literature focusing on high-performance practices in the Balkan region (Szamosi et al., 2010). Due to the majority of research conducted in western Anglo-Saxon as well as the Asian region (e.g. Fey et al., 2009; Chen et al., 2005; Takeuchi et al., 2007), there is a lack of understanding of how high-performance measurements operate in organizations within the Balkan region. This can have serious practical implications for MNE subsidiaries operating in the region and their effort of introducing HPWS.

For this purpose, the current study will use a diverse sample of MNE subsidiaries operating in 6 former communist Balkan countries. The main reason for inclusion was the common cultural legacy brought by the communist area that makes this group of emerging economies an interesting case for 
analysis. The study aims not only to assess the HPWS organizational performance link in the specific cultural background but also to address the gap of research and literature in the area.

\section{Data and Methodology}

\subsection{Design}

The study employed primary quantitative data collected between August and November 2020. The sample was recruited from 6 former communist countries present in the proximity of the Balkan region (Albania, Bulgaria, Kosovo, Romania, Serbia, FYROM) using country specific National Management Associations. The language of communication and of data collection was English.

\subsection{Participants}

The study used a sample of 181 participants (females $\mathrm{N}=82$, males $\mathrm{N}=99$ ) working in MNE subsidiaries operating in former communist Balkan countries. The inclusion criteria were a high command of English language and a supervision position in an MNE subsidiary operating in the 6 post-communist Balkan countries (Albania, Bulgaria, Kosovo, Romania, Serbia, \& FYROM). An initial number of 250 questionnaires were received from the organizations from which a total number of 69 questionnaires were excluded from the study due to incompleteness or them being filled inappropriately.

\subsection{Measures}

All questionnaires were collected using hard-copies. The questionnaires were either distributed in person or posted to the researcher. High performance working systems scale was designed specifically for this study. The scale contains 20 items scored on a 7-point Likert scale rated from 1 (not at all) to 7 (great extent). Cronbach alpha was 0.95 . The Organizational culture scale (Chatterjee, Lubatkin, Schweiger, \& Weber, 1992) was used to assess the cultural environment within the organization. The scale includes 8 items scored on a 7-point Likert scale rated from 1 (not at all) to 7 (great extent) with a Cronbach`s alpha was 0.85 .

Job satisfaction was assessed using the General Satisfaction scale of the Minnesota Satisfaction Questionnaire (MSQ) (Arvey and Gross, 1977). The short-scale was used to assess the level of employee satisfaction with the current work position. The scale comprises 20 questions assessed on a 7-point Likert scale rated from 1(not at all) to 7 (very) with a Cronbach's alpha of 0.93. Accordingly, organizational citizenship behavior was measured using the 16-item scale adopted by Lee and Allen (2002) scored on a 7point likert scale rated from 1 (not at all) to 7 (very likely) with a Cronbach's alpha of 0.93. In parallel, organizational performance was measured using the 8-item scale taken from Vasilaki (2011), which assessed the perceived organizational financial performance. The scale scored on a 7-point Likert scale rating from 1 (low satisfaction) to 7 (high satisfaction) with a Cronbach's alpha of 0.92 .

\subsection{Procedure}

The participating organizations were recruited using data from the National Management Association of each country. Initial contact was conducted on the phone with the general manager of the subsidiaries and their secretary. During the phone call, they were asked if they agree to participate in a study assessing HR practices and how this can improve organizational performance. Upon acceptance, the manager appointed a person from the organization who would complete our questionnaire. The scales were posted to the person together with a consent form and a cover letter in July. The cover letter included details about the nature of the study, addresses and phone numbers of the principal investigator, the participant's anonymity and his/her answers, and the option to renounce the study at any given point. The participants had three weeks until August to post back the questionnaires, access the online form of the scales, or call 
the researcher to collect them directly from the organization. Due to the low response rate the deadline was extended until the end of October with one phone reminder every two weeks.

\subsection{Statistical Analysis}

The questionnaires were checked for missing data. Questionnaires with more than $15 \%$ missing data were dismissed from the study. The data was checked for normal distribution, and the missing data was replaced with the items mean. Factor analysis was performed as a data reduction tool. Based on factor analysis, 5 items were identified: HPWS scale, Leadership and organizational culture, Organizational citizenship behavior, Job Satisfaction, and Financial performance. Cronbach alpha was 0.88. Correlation matrices were also performed for the five scales.

We examined our present hypotheses using the bootstrapping technique (1000 bootstrap samples with 95\% confidence intervals) as suggested by Preacher and Hayes (2008). This technique allows us to encompass multiple mediators. Results (Table 1) indicated that HPWS are positively related to organizational performance $(\mathrm{B}=.40, \mathrm{p}<.01)$. Hence, hypothesis 1 was supported. Similarly, hypotheses 2 and 3, stating that job satisfaction and OCB mediate the relationship between HPWS and organizational performance, were supported since the bias-corrected confidence intervals of these indirect effects did not include zero (.03 and .21;.01 and .08). Last, the results found support for hypothesis 4 , which proposed that job satisfaction and OCB sequentially mediated the association between HPWS and organizational performance since the respective intervals did not also contain zero (.01 and .10).

Table 1. Path Coefficients and Indirect Effects for Mediation Models

\begin{tabular}{|c|c|c|c|c|c|}
\hline & Path coefficients & \multicolumn{4}{|l|}{ Indirect effects } \\
\hline & Organizational & Job satisfaction & $\mathrm{OCB}$ & Estimate & Bootstrap 95\% \\
\hline & Performance & & & & Confidence Interval \\
\hline HPWS & $0.40(0.07)$ & $0.45(0.05)$ & $0.13(0.05)$ & & \\
\hline Job satisfaction & $0.26(0.09)$ & & $0.41(0.06)$ & & \\
\hline OCB & $0.22(0.10)$ & & & & \\
\hline Total & & & & $.18(.05)$ & $.10, .28$ \\
\hline $\mathrm{HPWPS} \rightarrow \mathrm{JS} \rightarrow \mathrm{OP}$ & & & & $.12(.06)$ & $.03, .21$ \\
\hline $\mathrm{HPWS} \rightarrow \mathrm{OCB} \rightarrow \mathrm{OP}$ & & & & $.03(.02)$ & $.01, .08$ \\
\hline $\mathrm{HPWS} \rightarrow \mathrm{JS} \rightarrow \mathrm{OCB} \rightarrow \mathrm{OP}$ & & & & $.04(.02)$ & $.01, .10$ \\
\hline
\end{tabular}

All path coefficients are significant

Standard error in parentheses.

\section{Discussion}

\subsection{Theoretical Implications}

The current study aims at offering an in-depth analysis of the high-performance working systems and organizational performance measures. Recent years showed an increased interest in organizational performance with a switch from the traditional financial performance. As previously state, research shows a strong link between HPWS and organizational financial performance (e.g. Beltrain-Martin et al., 2008). Furthermore, studies reported the interactions of factors such as OCB (Buentuello et al., 2008), job satisfaction (Crossman and Zaki, 2003), and national culture (Fey, 2005) in the HPWS organizational financial performance link.

Hypothesis 1, 2, and 3 have been fully supported. We found that HPWS predicts organizational performance. Furthermore, it was found that HPWS predicts levels of OCB in foreign subsidiaries operating in former communist countries. Organizational citizenship behavior is linked to organizational performance. In other words, high levels of OCB predict high organizational performance. These findings are in line with the literature linking OCB with HPWS (Cong et al., 2010) and organizational performance (Buentello et al., 2008; Murphy et al., 2002). Hypothesis 4 was partially supported. Accordingly, 
organizational citizenship behavior partially mediated the relationship between HPWS and organizational performance. Furthermore, a direct positive link between HPWS and job satisfaction was found supporting hypothesis 5. Hypothesis 6 was fully supported. Job satisfaction was positively related to organizational performance, with job satisfaction predicting organizational performance. The findings are in line with previous research (Fey, 2005; Huang and van de Vliert, 2003). The findings showed only a partial mediation of job satisfaction on the HPWS organizational performance link.

The results might be explained in terms of the sample size. Mediation analysis shows better results in large samples with more rigorous statistical approaches such as the Sobel test (1982). Sobel (1982) uses a higher rigor of data analysis than the classical Barron and Kenny (1986) approach. However, the Sobel test can only be performed on large samples. Furthermore, Baron and Kenny (1986) argue that full mediation is rather rare, with the high majority or mediation models presenting partial mediation. Moreover, the model assessed a single mediating variable (OCB, job satisfaction). Thus, future studies might consider adopting other mediating variables that might impact the HPWS performance relationship. Likewise, variables such as employee motivation, organizational commitment, and organizational trust might impact the HPWS performance link.

\subsection{Practical Implications}

The current organizational climate in the Balkan region is characterized by economic difficulty and uncertainty (Milikic et al., 2008). To cope with this climate, both local and foreign organizations try to employ high-performance work practices that could offer them a competitive advantage. Our study is congruent with the literature advocating the positive role of HPWS in enhancing organizational performance. An organization that effectively implements such HPWS is likely to show favourable employee outcomes and consequently organizational performance. The results showed a positive relationship between HPWS and organizational performance. Thus, an organization adopting HPWS would experience an increase in financial performance. Furthermore, the mediating factor of job satisfaction and OCB offers managers a clearer view of the mechanisms present in the HPWSorganizational performance link.

The present study offers starting platform by creating a model of variables influencing the effective implementation of HPWS as well as the factors influencing organizational financial performance. Furthermore, emerging economies in the Balkan region saw an increase in foreign direct investment due to the increase in MNE subsidiaries operating in the region (Szamosi et al., 2010). However, due to the lack of literature in the area, such organizations have a tendency to either adopt the local organizational culture (Prodan et al., 2001) or implement western HR practices (Szamosi et al., 2010). The present study looks at the HPWS organizational performance model in light of MNE subsidiaries operating in 6 post-communist countries in the Balkan region. The study offers organizations operating in the region a starting point in the efficient adoption of HPWS.

\subsection{Limitations and Further Research}

The current study has some limitations that need further attention. For example, organizational financial performance was measured by using a set of self-evaluation items that can be subjective. The study did not use a set of objective financial indications for each organization employed. This might prove problematic in light of the diversity of employees participating in the study who might or might not be aware of the organizational financial indicators. The study used both middle managers and employees working in different departments within each company. Thus, it can be feasible to presume that the degree of financial understanding in general and organizational financial performance, in particular, will vary from department to department and from individual to individual. Furthermore, research shows that 
management might have a tendency to over-report the organizational financial situation (Liao et al., 2009). This might be due to social bias or to protect a secret agenda.

Furthermore, the main assumption of the study is that all participants are currently employed by MNE subsidiaries operating in the region. Even though the selection and sampling procedure was objectively performed to ensure that all the participating respondents are from MNE subsidiaries, there might be cases where individuals not working in MNE subsidiaries might have infiltrated in the study. The researcher had initially contacted the general managers of foreign MNC subsidiaries. The general manager's role was to appoint someone within the organization who would be able to facilitate in this regard. Although the possibility of the participants being employees from other organizations is minimal yet still, it exists. Future studies should be aware of this and employ a strict selection procedure as well as including an item asking the participant if he/she is working in MNE subsidiaries.

Lastly, the study (communication and questionnaires) has been conducted in the English language. This was done in an attempt to avoid limitations accompanying the translation and intra-country comparison problems. The main reason behind it was that English language is the main communication language in many multinational organizations (Kaur and Clarke, 2009). However, the study failed to test participants on their linguistic abilities, nor did it take into consideration English language exam scores. Thus, there is a small possibility that not all organizations presented in the study have a high criterion of English language skills for all their employees.

Regardless of its limitations, the present research brings an in-depth insight into the relationship between high-performance organizational systems and organizational financial performance in MNE subsidiaries operating in former communist emerging markets in the Balkan region. As previously stated, there is a lack of literature looking at the impact of HPWS implementation in MNE subsidiaries operating in the region. The current study offers a basis for further research in the region. Future studies should attempt an inter-country comparison as well as the employment of causal statistical tests. Furthermore, a comparison of HPWS implementation and organizational performance in foreign MNC subsidiaries and local MNE would offer further understanding in the field.

\section{References}

Apospori, E., Nikandrou, I., Brewster, C., \& Papalexandris, N. (2008). HRM and organizational performance in northern and southern Europe. The International Journal of Human Resource Management, 7(19), 1187-1207.

Alzyoud, A. A. Y., Ahmed, U., AlZgool, M. R. H., \& Pahi, M. H. (2019). Leaders' emotional intelligence and employee retention: Mediation of job satisfaction in the hospitality industry. International Journal of Financial Research, 10(3), $1-10$.

AlZgool, M., Ahmed, U., Shah, S., Alkadash, T., \& AlMaamary, Q. (2021). Going green during COVID-19: Examining the links between green HRM, green supply chain and firm performance in food Industry of Bahrain: The moderating role of lockdown due to COVID-19. Uncertain Supply Chain Management, 9(1), 79-88.

Bashir, M., Jianqiao, L., Jun, Z., \& Ghanzafar, F. (2011). The role of demographic factors in the relationship between high performance work systems and job satisfaction: a multidimensional approach. International Journal of Business and Social Science, 18(2), 207-218.

Bass, B., \& Avolio, B. (2004). MLQ Multifactor Leadership Questionnaire for Research. Redwood City, CA: Mind Garden.

Becker, B.E., \& Huselid, M.A. (1998). High Performance Work Systems and firm performance: a synthesis of research and managerial implications. Research in personnel and Human Resources Management, 16, 53-101.

Bedo, Z., Demirbag, M., \& Wood, G. (2011). Introducing governance and employment relations in Eastern and Central Europe. Employee Relations, 4(33), 309-315.

Beltran-Martin, I., Roca-Puig, V., Escrig-Tena, A., \& Bou-Llusar, J.C. (2008). Human Resource flexibility as a mediating variable between high performance work systems and performance. Journal of Management, 34(5), $1009-1046$.

Boxall, P., \& Macky, K. (2009). Research and theory on high-performance work systems: progressing the highinvolvement stream. Human Resource Management Journal, 1(19), 3-23. 
Brewster, C., \& Bennett, C.V. (2010). Perceptions of business cultures in Eastern Europe and their implications for international HRM. The International Journal of Human Resource Management, 14(21), 2568-2588.

Brewster, C., Mayrhofer, W., Morley, M. (2004). Human Resource Management in Europe: Evidence of Convergence?, Elsevier Butterworth-Heinemann.

Buentello, O., Jung, J., \& Sun, J. (2008). exploring the casual relationship between organizational citizenship behavior, total quality management, and performance. Southwest Decision Science Institute. 78-87.

Chen, S.J., Lawler, J.J., \& Bae, J. (2005). Convergence in Human resource systems: a comparison of locally owned and MNC subsidiaries in Taiwan. Human Resource Management, 44(3), 237-256

Crossmas, A. \& Zaki, B.A. (2003). Job satisfaction and employee performance of Lebanese banking staff. Journal of Managerial Psychology, 18(4), 368-376.

Fey, C.F., Morgulis-Yakushev, S., Park, H.J., \& Bjorkman, I. (2009). Opening the black box of the relationship between HRM practices and firm performance. A comparison of MNE subsidiaries in the USA, Finland, and Russia. Journal of International Business Studies, 40(4), 690-712.

Gittell, J.H., Seidner, R., \& Wimbush, J. (2009). A relational model of how High-Performance Work Systems work. Organization Science, 2(21), 1-17.

Gong, Y., Chang, S., and Cheng, S.Y. (2010). High performance work system and collective OCB: a collective social exchange perspective. Human Resource Management Journal, 20(2), 119-137.

Harter, J. K., Schmidt, F. L., \& Hayes, T. L. (2002). Business-unit level relationship between employee satisfaction, employee engagement, and business outcomes: A meta-analysis. Journal of Applied Psychology, 87, $268-279$.

Hayes, F. A., (2009). Beyond Baron and Kenny. Statistical analysis in the new millenium. Communication Monograms, $76(4), 408-422$.

Jamal, M. (2011). Job stress, job performance, and organizational commitment in a multinational company: an empirical study in two countries. International Journal of Business and Social Sciences. 2(20), 20-29.

Jiang, J.Y., Sun, L.Y., \& Law, K.S. (2011). Job Satisfaction and organizational structure as moderators of the effects of empowerment on organizational citizenship behavior: a self-consistency and social exchange perspective. International Journal of Management, 28(3), 675-693.

Katou, A. A. (2009). The impact of human resource development on organisational performance: Test of a causal model. Journal of Behavioral and Applied Management, 10(3), 335-356.

Kaur, S., \& Clarke, C.M. (2009). Analysing the English language needs of human resource staff in multinational companies. English for specific purposes, 3(24), 1-10.

Kintara, M.L., Alonso, A.U., \& Olaverri, C.G. (2006). High-performance work systems and firms' operational performance: the moderating role of technology. International Journal of Human Resource Management, 17(1), 70-85.

Lee, K., \& Allen, N. J. (2002). Organizational citizenship behavior and workplace deviance: The role of affect and cognition. Journal of Applied Psychology, 87(1), 131-142.

Liao, H., Toya, K., Lepak, D.P., \& Hong, Y. (2009). Do they see eye to eye? Management and employee perspectives of High-Performance Work Systems and influence processes on service quality. Journal of Applied Psychology, 94(2), 373-391.

Luo, Y., and Tang, R.L. (2007), International Expansion of Emerging Market Enterprises: A Springboard Perspective, Journal of International Business Studies, 38, $481-489$.

Menard, S. (1995). Applied Logistic Regression Analysis. Sage Publications. Series: Quantitative Applications in the Social Sciences, (106).

Milikic, B.B., Janicijevic, N., \& Petkovic, M. (2008). HRM in transition economies: the case of Serbia, South East European Journal, 14, 75-88.

Myers, R.H. (1990). Classical and modern regression application. 2nd edition. John Wiley. New York.

Organ, D. W. (1997). Organizational citizenship behavior: It's construct cleanup time. Human Performance, $10(2), 85-97$.

Ostroff, C. (1992). The relationship between satisfaction, attitudes, and performance: An organizational Level Analysis. Journal of Applied Psychology, 77, 963-974.

Pare, G. \& Tremblay, M. (2007). The influence of High-Involvement Human Resources Practices, precedural justice, organizational commitment, and citizenship behaviors on information technology professionals' turnover intentions. Group E Organizational Management,32(3), 326-357.

Podsakoff P. M., Ahearne M., \& MacKenzie, S. B. 1997. Organizational citizenship behavior and the quantity and quality for work group performance. Journal of Applied Psychology, 82(2), 262-270. 
Podsakoff, P. M., Mackenzie, S. B., Paine, B. P., \& Bachrach, D. G. (2000). Organizational citizenship behavior: A critical review of the theoretical and empirical literature and suggestions for future research. Journal of Management, 26 (3), 513-563.

Prodan, A., Chirlesan, T., \& Brailean, I.T. (2001). Management în administratie (Management administration), Iasi, Sedcom Libris.

Sahadev, S. and Demirbag, M. (2010). A comparative analysis of employment practices among post-communist and capitalist countries in South Eastern Europe. Employee Relations, 32(3), 248-261.

Snape, E., \& Redman, T. (2010). HRM practices, organizational citizenship behavior, and performance: a multi-level analysis. Journal of Management Studies,47(7), 1220-1247.

Sobel, M. E. (1982). Asymptotic confidence intervals for indirect effects in structural equation models. In S. Leinhardt (Ed.), Sociological Methodology 1982. (pp. 290-312). Washington DC: American Sociological Association.

Stephan, J., and Jindra, B. (2005). Knowledge transfer to MNE subsidiaries based in Central East Europe- Integradting knowledge-based and organizational perspectives. An introduction. Journal of East-West Economics and Business, 3 , 11-18.

Sun, L.Y., Aryee, S. and Law, K.S. (2007). 'High-performance human resource practices, citizenship behaviors and organizational performance: a relational perspective'. Academy of Management Journal, 50(3), 558-577.

Svetlik, I., Barisic, A.F., Kohont, A., Petkovic, M., Miric, A.A., Slavic, A., Vaupot, Z., \& Poor, J. (2010). Human Resource Management in the countries of the former Yugoslavia. Review of International Comparative Management, 11(5), 807833.

Svetlik, I., Barisic, A.F., Kohont, A., Petkovic, M., Miric, A.A., Slavic, A., Vaupot, Z., \& Poor, J. (2010). Human Resource Management in the countries of the former Yugoslavia. Review of International Comparative Management, 11(5), 807833.

Szamosi, L., Wilkinson, A., Wood, J., and Psychogios, A. (2010). Developments in HRM in south-eastern Europe. The International Journal of Human Resource Management, 21(14), 2521-2528.

Takeuchi, R., Lepak, D.P., Wang, H., \& Takeuchi, K. (2007). An empirical examination of the mechanisms mediating between High-Performance Work Systems and the performance of Japanese organizations. Journal of Applied Psychology, 4(92), 1069-1083.

Tsai, C.J. (2006). High performance work systems and organizational performance: an empirical study of Taiwan's semiconductor design firms. International Journal of Human Resource Management, 17(9), 1512-1530.

Tsai, C.J., Edwards, P., \& Sengupta, S. (2010). The associations between organizational performance, employee attitudes and human resource management practices. An empirical study of small businesses. Journal of General Management, 1(26), 1-20.

Umrani, W. A., Siyal, I. A., Ahmed, U., Ali Arain, G., Sayed, H., \& Umrani, S. (2019). Does family come first? Family motivation-individual's OCB assessment via self-efficacy. Personnel Review, 49(6), 1287-1308.

Vasilaki, A. (2011). The relationship between transformational leadership and postacquisition performance. International Studies of Management \& Organization, 41(3), 42-58.

Wu, P. C., \& Chaturvedi, S. (2009). The role of procedural justice and power distance in the relationship between high performance work systems and employee attitudes: a multilevel perspective. Journal of Management, 35(5), 12281247.

Young, S., Bartram, T., Staton, T., \& Leggat, S. (2010). High performance work systems and employee well-being: a two-stage study of a rural Australian hospital. Journal of Health Organizational Management, 24(2), 182-199.

(C) 2021 by the author(s). Published by Annals of Contemporary Developments in Management \& HR (ACDMHR), under the terms and conditions of the Creative Commons Attribution (CC BY)

license which can be accessed at http://creativecommons.org/licenses/by/4.0. 